\title{
Indacaterol therapy in moderate-to-severe chronic obstructive pulmonary disease: findings from a single-center primary care cohort
}

This article was published in the following Dove Press journal:

International Journal of COPD

7 December 2013

Number of times this article has been viewed

\author{
Mukesh P Singh \\ Horsefair Practice Group, Sandy \\ Lane Health Centre, Rugeley, UK
}

Correspondence: Mukesh P Singh Horsefair Practice Group, Keele University Medical School Teaching Practice, Sandy Lane Health Centre, Sandy Lane, Rugeley, Staffordshire WSI5 2LB, UK Tel +44 I889 582244 Emailmps_67@yahoo.com
Background: Once-daily long-acting $\beta_{2}$-agonists (LABAs) are an important treatment option, either alone or in combination with other inhaled long-acting bronchodilators in the management of chronic obstructive pulmonary disease (COPD).

Aims/objectives: To audit the effectiveness of indacaterol as maintenance therapy in patients with moderate-to-severe COPD (Global initiative for chronic Obstructive Lung Disease [GOLD] stage II/III).

Methods: This was a single-center audit of a primary care COPD cohort comprising all patients treated with indacaterol following treatment escalation (as per National Institute for Health and Care Excellence guidelines) or failure with other therapies. The sample was restricted to patients treated for a minimum of 12 months with indacaterol, for whom preswitching and follow-up spirometry as well as exacerbation frequency data were available (GOLD spirometry guidelines). Pulmonary function was assessed by spirometry (recorded as forced expiratory volume in 1 second $\left[\mathrm{FEV}_{1}\right]$ expressed as percentage predicted). Relevant self-reported qualitative information was recorded in descriptive terms for quality of life (QoL) assessment.

Results: A total of 15 patients met the audit inclusion criteria (66.6\% male, mean age 64.9 \pm 7.7 years). COPD disease duration ranged from 1 to 22 years; $93 \%$ had GOLD stage II or III COPD. Follow-up ranged in duration from 12 to 27 months. Indacaterol was associated with a significant reduction in exacerbation frequency compared with the 12 months prior to initiation $(P=0.02)$. In those patients who experienced three or more exacerbations/year, mean exacerbation rate fell from $5.43 \pm 1.07$ to $2.43 \pm 0.2$ after 12 months treatment with indacaterol $(P=0.02)$. A reduction in dyspnea was noted in $53 \%$ of patients. Similarly, improvements in exercise tolerance and well-being were self-reported in $67 \%$ and $93 \%$, respectively.

Conclusion: Indacaterol was found to be an effective LABA as an escalation or switch medication in patients with moderate-to-severe COPD. Indacaterol was effective both as monotherapy and in combination with a long-acting muscarinic antagonist. Switching to indacaterol from a LABA/inhaled corticosteroid fixed-combination inhaler significantly reduced the number of acute exacerbations and also improved self-reported QoL.

Keywords: chronic obstructive pulmonary disease, primary care, audit, indacaterol, bronchodilators, effectiveness

\section{Introduction}

Chronic obstructive pulmonary disease (COPD) is a progressive disorder characterized primarily by airflow limitation, resulting in exertional dyspnea with expiratory wheeze, cough, and sputum production. Patients often experience acute exacerbations with progressive worsening of symptoms, which can have a significant impact on functional capacity and health-related quality of life (QoL). In the UK, as seen in other 
developed countries, ${ }^{1-3} \mathrm{COPD}$ is a major cause of morbidity and mortality, and poses a major burden to society not only in terms of cost to health care services but also through loss of productivity. ${ }^{3,4}$

Although recommended treatment and selection criteria vary slightly across current guidance, broad consensus exists for pharmacotherapy. ${ }^{1-3}$ Most recommendations are based upon disease severity, with assessment and stratification primarily based upon respiratory function, as measured by forced expiratory volume in 1 second $\left(\mathrm{FEV}_{1}\right)$ expressed as percentage predicted. While the Global initiative for chronic Obstructive Lung Disease (GOLD) guidelines stratify patients into four groups (GOLD stages I-IV) based upon a range of $\mathrm{FEV}_{1} \%$ thresholds; in the UK the National Institute for Health and Care Excellence, endorsed by the British Thoracic Society, currently recommends treatment for two groups of patients, based upon whether $\mathrm{FEV}_{1}$ is $<50 \%$ or $\geq 50 \% .{ }^{5}$ Key treatment strategies include stepwise use of short-acting bronchodilators such as short-acting $\beta_{2}$-agonists (SABAs) or short-acting muscarinic antagonists (SAMAs) for relief of acute symptoms. In patients with GOLD stage I or in patients with disease progression, long-acting $\beta_{2}$-agonists (LABAs) or long-acting muscarinic antagonists (LAMAs) are recommended in suitable patients. Inhaled corticosteroids (ICS) are usually given in fixed combination with an LABA, although some patients may be reluctant to use or unable to tolerate ICS.

In clinical practice, there is a wide range of both agents and dosing schedules available for use, for which the supporting evidence is derived primarily from a number of large randomized controlled trials. Indacaterol, the first ultra-long-acting LABA to be approved with a 24-hour bronchodilatory effect allowing for once-daily administration, is an important treatment option, alone or in combination with other inhaled long-acting bronchodilators. ${ }^{6-8}$ Widely investigated prior to approval in six Phase III, randomized, double-blind trials, indacaterol significantly improved lung function when compared with placebo, tiotropium, formoterol, and salmeterol, ${ }^{7,9,10}$ and has been shown to reduce dyspnea, lower rescue-medication use, improve QoL, reduce the incidence and number of exacerbations, and delay the time to both first exacerbation and first hospitalization, particularly when compared with placebo..$^{6,8,9,11,12}$ In our primary care practice, which treats more than 300 patients with COPD, a range of audits are now undertaken, including audit of those patients with moderate-to-severe COPD requiring therapy escalation or switching because of poor symptom control or exacerbation frequency. Reported here are the results of one such audit: that of patients switched from existing therapy to treatment with indacaterol, either as monotherapy or in combination with other licensed agents. This group, which forms about $5 \%$ of our COPD patients, was audited for changes in exacerbation rate, lung function, and self-reported patient-centered outcomes on QoL after 12 months of treatment with indacaterol.

\section{Materials and methods}

Data were collected for all patients treated with indacaterol following treatment escalation or treatment change because of failure with other therapies. Inclusion for analysis was restricted to patients treated for a minimum of 12 months with indacaterol for whom pre-initiation and follow-up spirometry and exacerbation frequency data were available. Treatment failure was defined as poor symptom control, with increasing dyspnea and frequency of exacerbations while on treatment with approved COPD therapies. COPD exacerbation was characterized as a physician visit during which a clinical diagnosis of acute exacerbation was made (productive cough, dyspnea, and worsening of symptoms, requiring prescription of an oral corticosteroid or antibiotic within 5 days of the visit), or where hospital referral was necessary. ${ }^{13}$ Classification of COPD severity was based on spirometric guidelines of GOLD. Pulmonary function was assessed by spirometry (recorded as $\mathrm{FEV}_{1} \%$ predicted). In all patients, spirometry was performed using a SpidaXpert (CareFusion, Höchberg, Germany) spirometer following bronchodilation with salbutamol; the findings were analyzed using SpidaXpert software.

For audit purposes, treatment duration was defined as the first record of a prescription for indacaterol (the index date) to the date of data extraction (April 2013). COPD medication use (ie, pre-initiation) on the index date was recorded. Annual exacerbation rates over a 12-month period before and after initiation of indacaterol were compared. A subgroup of patients with frequent exacerbations, defined as patients who had three or more exacerbations in the 1-year period prior to indacaterol, were identified for a separate subgroup analysis.

\section{Outcome assessment}

Pulmonary function, the total number of exacerbation events, and the annual exacerbation rate occurring within the follow-up period were the chosen audit outcomes, in part as such data is recorded in routine clinical care. Also recorded in descriptive terms based upon patient interviews at assessment was self-reported qualitative information for 
QoL assessment, including dyspnea severity, exercise tolerance, general feeling of well-being, and satisfaction with current therapy.

\section{Statistical analysis}

Data are presented as means \pm standard deviation (SD) for continuous outcomes, and counts and percentages for categorical variables. The percentage of patients with at least one COPD exacerbation and the number of unique exacerbations were described in the overall sample and the subgroup with at least three exacerbations in the previous year. Comparisons of respiratory function and exacerbation rates in the 1-year period prior to the index date and after indacaterol were made using a paired $t$-test, with statistical significance set at $P<0.05$.

\section{Results}

Our records identified 15 patients who received indacaterol either alone or in conjunction with existing therapies for a minimum of 12 months (66.6\% male, age $64.9 \pm 7.7$ years, Table 1). Twelve patients were ex-smokers and three were current smokers, while two patients also had a history of occupational dust exposure. Comorbid conditions of note included tuberculosis in one patient and steroid-associated Cushingoid changes in another. COPD disease duration ranged from 1 to 22 years; $93 \%$ had moderate-to-severe GOLD stage II or III COPD. Follow-up ranged from 12 to 27 months. At the index visit (prior to indacaterol initiation), patients were receiving a range of established agents, including SABA (salbutamol) or LAMA (tiotropium) monotherapy, and multiagent regimens involving an SABA, SAMA, LABA, LAMA, and ICS in various combinations (see Table 1). All patients used an SABA as rescue medication as needed. Eight (53\%) patients were receiving fixeddose ICS/LABA inhaler, four of whom were also receiving tiotropium (as triple therapy), while the remaining seven (47\%) were receiving monotherapy, either an SABA $(n=3)$, an SAMA $(n=1)$, or tiotropium $(n=3)$.

Treatment failure is characterized in Table 1. In all patients, poor symptom control was documented, with frequent exacerbations also documented in six patients. Treatment-related adverse effects with steroid therapy were also reported; one patient declined ICS and chose to receive indacaterol as an alternative agent. Indacaterol replaced LABA/ICS in seven out of eight patients, and was given as escalated treatment in addition to tiotropium in five patients. All patients received indacaterol delivered via the Breezhaler ${ }^{\circledR}$ (Novartis, Basel, Switzerland) device at an initial once-daily dosing of 150
Table I Baseline demographics and clinical characteristics of included patients

\begin{tabular}{|c|c|}
\hline & $n=15$ \\
\hline \multicolumn{2}{|l|}{ Age, years } \\
\hline Mean (SD), range & 64 (7.7), 52-74 \\
\hline \multicolumn{2}{|l|}{ Sex, n (\%) } \\
\hline Male & $10(66.6)$ \\
\hline Female & $5(33.3)$ \\
\hline Mean (SD) duration of COPD, years, range & $6.3(6.0), \mathrm{I}-22.5$ \\
\hline \multicolumn{2}{|l|}{ COPD severity, n (\%) } \\
\hline Mild & I (6.7) \\
\hline Moderate & $9(60)$ \\
\hline Severe & $5(33.3)$ \\
\hline Very severe & - \\
\hline \multicolumn{2}{|l|}{ Smoking status, n (\%) } \\
\hline Ex-smoker & $12(80)$ \\
\hline Current smoker & $3(20)$ \\
\hline Mean (SD) preswitching postbronchodilator & $54.2(15.3)$ \\
\hline \multicolumn{2}{|l|}{ FEV $\%$ predicted } \\
\hline \multicolumn{2}{|l|}{ COPD exacerbation history, $\mathrm{n}(\%)$} \\
\hline 0 & - \\
\hline I & $3(20)$ \\
\hline$\geq 2$ & $8(72.7)$ \\
\hline \multicolumn{2}{|l|}{ Indication for switching, n (\%) } \\
\hline Poor symptom control & $15(100)$ \\
\hline Frequent ( $\geq 3 /$ year) exacerbations & $6(40)$ \\
\hline Unsuitable for ICS & $3(20)$ \\
\hline \multicolumn{2}{|l|}{ Preswitching agents, n (\%) } \\
\hline SAMA/SABA & $4(26.7)$ \\
\hline LAMA & $3(20)$ \\
\hline LABA/ICS & $4(26.7)$ \\
\hline LAMA + LABA/ICS & $4(26.7)$ \\
\hline \multicolumn{2}{|l|}{ Postswitching agents, n (\%) } \\
\hline Indacaterol & $3(20)$ \\
\hline Indacaterol + LAMA & II (73.3) \\
\hline Indacaterol + LAMA + LABA/ICS & I (6.7) \\
\hline $\begin{array}{l}\text { Mean (SD) duration of treatment postswitching, } \\
\text { months, range }\end{array}$ & $17.3(6.1), 12-27$ \\
\hline
\end{tabular}

Abbreviations: SD, standard deviation; COPD, chronic obstructive pulmonary disease; LABA, long-acting $\beta_{2}$-agonist; SABA, short-acting $\beta_{2}$-agonist; LAMA, long-acting muscarinic antagonist (tiotropium); SAMA, short-acting muscarinic antagonist; ICS, inhaled corticosteroids; $\mathrm{FEV}_{\text {, }}$, forced expiratory volume in I second as a percentage of forced vital capacity.

$\mu \mathrm{g}$. During follow-up, one patient was prescribed indacaterol $300 \mu \mathrm{g}$ once daily.

Complete spirometry data were available in 14 patients (Figure 1). While the majority of patients had moderate or severe COPD, as a group there were no significant changes in lung function $(P=0.39)$. Prior to switching, the mean (SD) $\mathrm{FEV}_{1} \%$ predicted across all these patients was $54.5 \%(15.8 \%)$, and at the last assessment (after a minimum of 12 months on indacaterol), 57.1\% (20.4\%). However, changes were seen on an individual patient basis. While spirometry was effectively unchanged in a third of patients, improvements were seen in a third and decline in the remainder. Exacerbation frequency was available in 13 patients (Figure 2). In the 12 months 
prior to indacaterol, eleven patients experienced one or more exacerbations (range 0-10, mean 3.31 \pm 0.87 , SD 3.15); in the follow-up period, exacerbation rate was significantly reduced (range $0-3$, mean $1.54 \pm 0.31$, SD 1.13; $P=0.02$ ). In six patients classified as suffering frequent exacerbations, mean exacerbation rate fell significantly from $5.43 \pm 1.07$ to $2.43 \pm 0.2$ after 12 months treatment with indacaterol $(P=0.02)$.

Treatment with indacaterol was generally well tolerated, with no adverse effects reported. Although not formally measured, patient satisfaction was high, with all patients

\section{A FEV $_{1} \%$ predicted assessment prior to and postswitching to indacaterol}

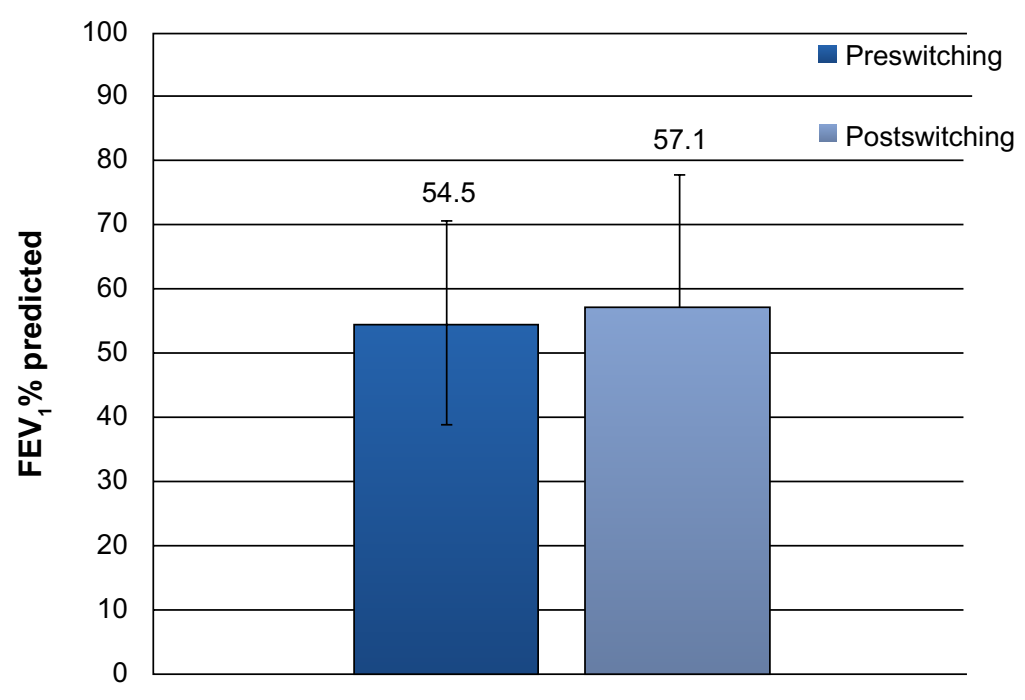

All patients

B Percentage change in $\mathrm{FEV}_{1} \%$ predicted after 12 months treatment with indacaterol

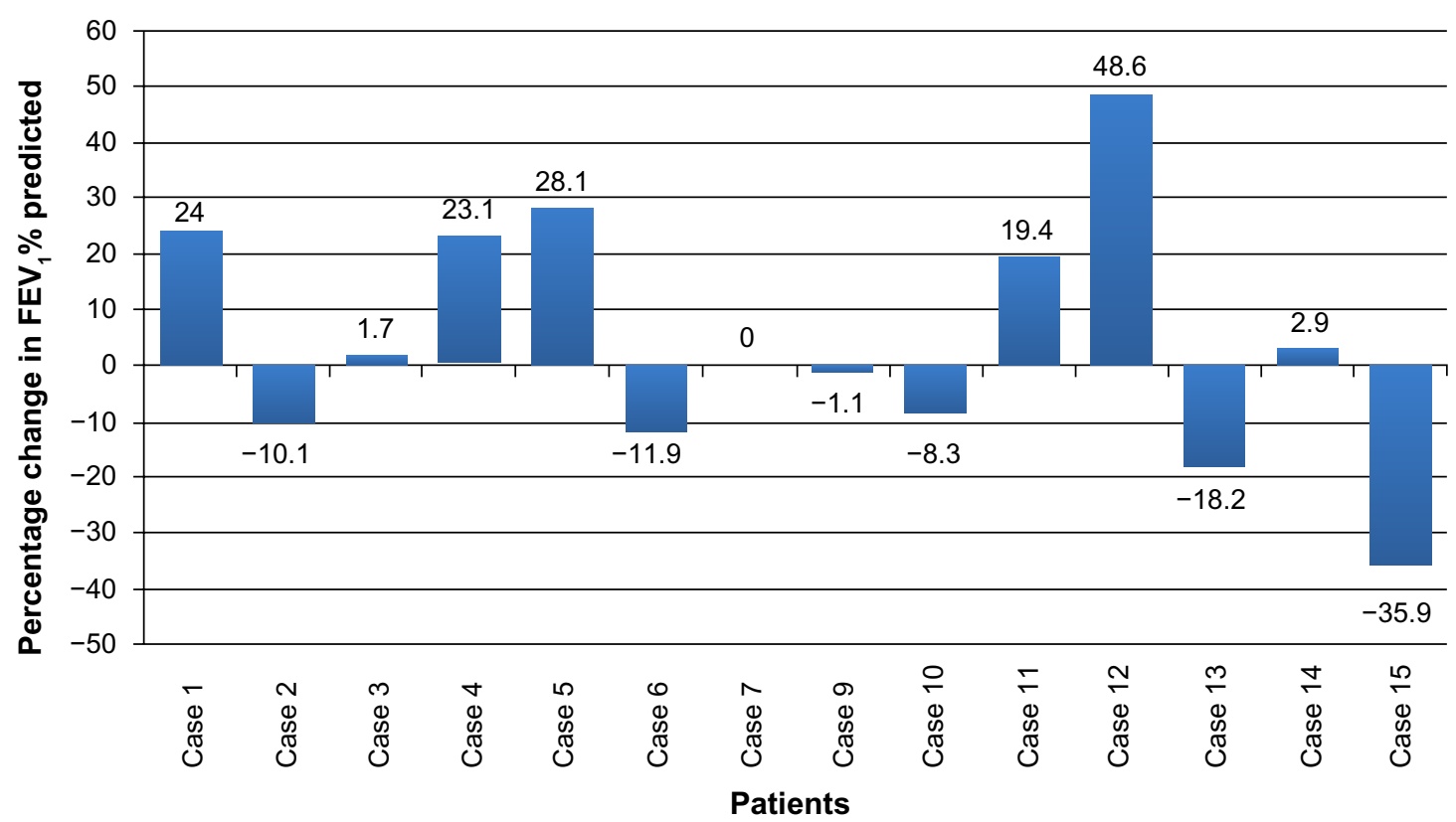

Figure I (A) Spirometry (FEV,\% predicted) prior to switching and after a minimum of 12 months of indacaterol treatment. Complete spirometry data were available for 14 patients. Prior to switching, the mean (SD) FEV \% predicted across all these patients was $54.5 \%$ (I5.8\%), and at the last assessment (after a minimum of I2 months on indacaterol) $57.1 \%(20.4 \%)$. No statistical differences in pre- and postswitching spirometry were seen, either for the cohort as a whole ( $P=0.39)$ or for comparisons based upon disease severity. (B) Individual percentage change in $\mathrm{FEV}_{1} \%$ predicted after a minimum of $\mathrm{I} 2$ months of indacaterol. Changes were seen on an individual patient basis. In five patients, notable improvement in spirometry was seen, while in five patients deterioration was observed; in four patients, FEV, was relatively unchanged. Abbreviations: $\mathrm{FEV}_{1}$, forced expiratory volume in I second as a percentage of forced vital capacity; SD, standard deviation. 


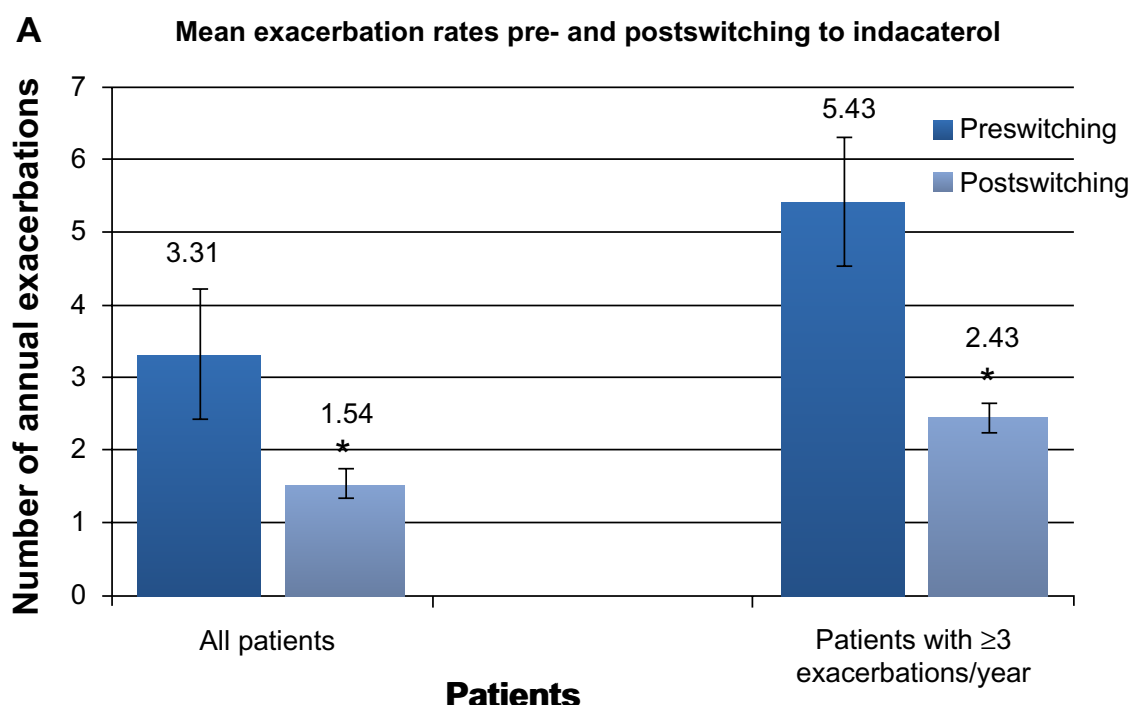

B

Individual annual exacerbations

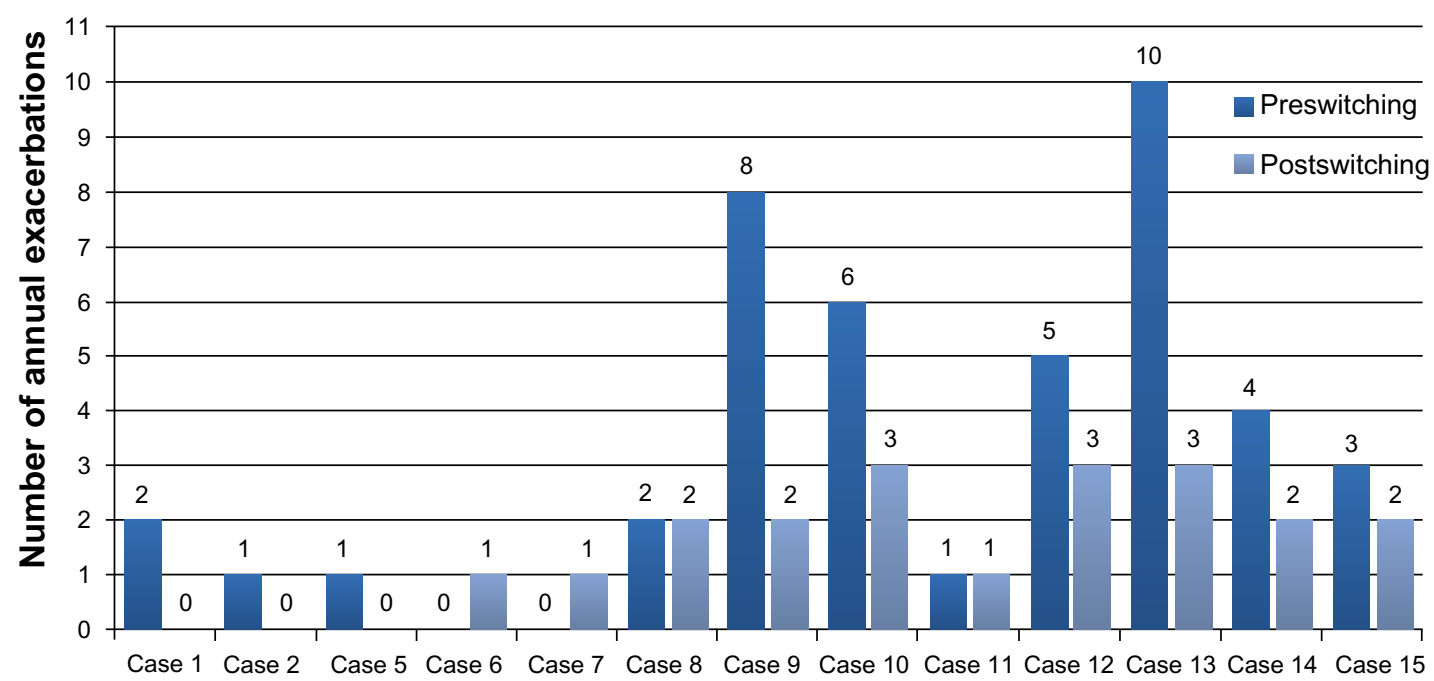

Patients

Figure 2 (A) Mean annual exacerbation rates immediately prior to and after a minimum of 12 months of indacaterol therapy. Exacerbation frequency was available in 13 patients. (range 0-10, mean $3.3 \mathrm{I} \pm 0.87, \mathrm{SD}=3.15$ ). Following switching to indacaterol, mean exacerbation rate fell significantly (range $0-3$, mean $1.54 \pm 0.3 \mathrm{I}, \mathrm{SD}=1.13$; $P=0.02$ ). In six patients classified as suffering frequent (three or more per year) exacerbations, mean exacerbation rate fell significantly from $5.43 \pm 1.07$ to $2.43 \pm 0.2$ after 12 months treatment with indacaterol $(P=0.02)$. $* P=0.02$. (B) Individual annual exacerbation rates in the 12 months prior to switching and the last 12 months of indacaterol treatment. On an individual patient basis, a reduction in frequency of acute exacerbations was seen in nine of 13 patients (69\%).

Abbreviation: SD, standard deviation.

wishing to continue with indacaterol as part of current therapy. Reduction in breathlessness (53\% of patients), improved exercise tolerance (67\%), and expressions of improved wellbeing (93\%) were reported after indacaterol.

The majority of patients did not show changes in the severity of COPD during the treatment period; on the basis of spirometry alone, three patients improved their GOLD stage (two patients improved from stage II to I and one patient from stage III to II), and two patients progressed from GOLD stage III to IV. However, both patients who showed progression from stage III to stage IV had reduction in exacerbation rate and also self-reported improvement in QoL.

\section{Discussion}

In this single-center primary care COPD cohort, our findings suggest that indacaterol had clinical benefits in patients with moderate-to-severe COPD who remained symptomatic and showed disease progression on alternative therapies and/or were intolerant of or reluctant to take ICS. The benefits (reduction in acute exacerbation rates with no significant 
deterioration in lung function, and improvements in QoL) are consistent with those reported in the clinical trial program for indacaterol and summarized in recent reviews $\mathrm{s}^{6,8}$ and are reassuring, especially as there were limited data reported from the primary care setting on switching from existing therapies to an indacaterol-containing regimen.

In this cohort, use of indacaterol alone or in combination with other agents for 12 months resulted in significant reductions in exacerbation rate compared with previous therapies. Of those patients who were switched to indacaterol due to frequent exacerbations (three or more in the last year prior to switching), a similar reduction in exacerbation rate was found. In some cases, substantial reductions in annual rate were seen, with one patient falling from ten to three, and another from eight to two per year (Figure 2). While previous placebo-controlled studies found that treatment with indacaterol resulted in reduced exacerbation rates, ${ }^{9,14}$ the data reported here suggest a benefit in patients failing active treatment in a primary care setting. These included four patients previously receiving triple therapy, three of whom responded when switched to an indacaterol based LABALAMA combination with steroid discontinuation.

Although the data regarding patient-reported QoL outcomes are descriptive rather than quantitative, a product of the retrospective nature of this study, the findings show a high level of satisfaction, with the majority describing improvements in well-being and exercise tolerance and reductions in dyspnea symptoms. Again, this is in keeping with current data for indacaterol. . $^{9,15}$

While no overall trend toward improvement or decline in $\mathrm{FEV}_{1} \%$ was found following use of indacaterol, the magnitude of individual improvements was greater than that for decline, although the significance of this finding is unclear. Two patients who showed progression from stage III to stage IV reported improvements in QoL and reduction in exacerbation rates. This raises the issue that reclassifying these patients as showing clinical disease progression purely based on spirometry may not be entirely appropriate, and indeed is in keeping with the growing recognition that, while important and reproducible, $\mathrm{FEV}_{1} \%$ values alone may be only weakly associated with other aspects of COPD disease status. $^{6}$

While the data reported here are consistent with the clinical benefits for indacaterol reported in prospective studies, it should be noted that in the majority of our patients, indacaterol was given in combination with tiotropium, a treatment combination compliant with recommended guidance for use of LABA-LAMA combinations in patients who remain symptomatic on existing therapy. ${ }^{1-3}$ As such, the benefits seen may relate to an effect of this indacaterol-tiotropium combination. While further data from ongoing studies are needed, current data suggest that indacaterol-LAMA combinations, including QVA149 (a fixed-dose combination of indacaterol and glycopyrronium), provide benefits across a variety of clinically important COPD outcomes compared with placebo and existing agents. ${ }^{16-20}$ In this context, our experience from a primary care setting supports the use of indacaterol as part of an LABA-LAMA combination approach. This includes those patients who either remain symptomatic with or are unable or unwilling to use ICS.

Aspects of this audit are of value. No such studies from a single-center primary care setting have reported on experience with the once-daily LABA indacaterol, which has been available for use since 2011. As such, it may be of interest to those working in a similar setting. However, as a study, it has a number of limitations, chiefly related to its retrospective/audit nature, small number of subjects (and risk of associated selection bias), and the fact that indacaterol was usually given along with other agents, in most cases tiotropium. Furthermore, until recently, quantitative assessments of QoL, such as St George's Respiratory Questionnaire scores, were not routinely performed in our clinical practice, and so quantitative preswitching and postswitching data were not available for patient-centered outcomes. Also, as the data extracted were derived from routine clinical practice rather than for study-specific purposes, there was no mechanism in place to capture other valuable information, such as patient diaries that routinely record the use of rescue medication. However, it is important to provide some information from the patient's perspective, which does indicate self-perceived benefits and treatment satisfaction. From a statistical perspective, the small number of patients $(n=15)$ and the absence of any external control group does not allow for more robust statistical analyses, and the unblinded nature of the study dictates that an element of physician and patient bias may exist with respect to evaluation of some end points. These limitations have been highly educational to our practice, with changes introduced to make ongoing and future audits and formal studies of our patients more robust. It is hoped that the experiences discussed in this report may act as a stimulus for similar work from other primary care settings, and that the open reporting of limitations inherent in this audit may be informative for colleagues.

In summary, indacaterol was found to be an effective treatment in suitable patients with moderate-to-severe COPD within a primary care setting. Its use alone or in combination 
with tiotropium significantly reduced the number of acute exacerbations. Benefits in self-reported QoL (dyspnea and exercise tolerance) were also seen.

\section{Acknowledgments}

The author wishes to thank the patients and staff of the Horsefair Practice Group. This article was developed from the author's presentation at the American Thoracic Society International Conference in Philadelphia in May 2013. The author also thanks the anonymous reviewers for their highly constructive comments and suggestions before the final publication of this article. Medical writing assistance was provided by Iain O’Neill, BDS, MSc, FDSRCSEd, DipRCPath and Ana Martins-Kaczor, $\mathrm{PhD}$ of Edge Medical Communications, funded by Novartis UK.

\section{Disclosure}

Dr Singh has received consulting and speaking honoraria from several pharmaceutical companies, including AstraZeneca, GlaxoSmithKline, Boehringer Ingelheim, Chiesi, Pfizer, and Novartis. The author reports no other conflicts of interest in this work.

\section{References}

1. Vestbo J, Hurd SS, Agustí AG, et al. Global strategy for the diagnosis, management, and prevention of chronic obstructive pulmonary disease: GOLD executive summary. Am J Respir Crit Care Med. 2013;187(4): 347-365.

2. Qaseem A, Wilt TJ, Weinberger SE, et al. Diagnosis and management of stable chronic obstructive pulmonary disease: a clinical practice guideline update from the American College of Physicians, American College of Chest Physicians, American Thoracic Society, and European Respiratory Society. Ann Intern Med. 2011;155(3):179-191.

3. O'Reilly J, Jones MM, Parnham J, Lovibond K, Rudolf M. Management of stable chronic obstructive pulmonary disease in primary and secondary care: summary of updated NICE guidance. BMJ. 2010;340:c3134.

4. Simpson CR, Hippisley-Cox J, Sheikh A. Trends in the epidemiology of chronic obstructive pulmonary disease in England: a national study of 51,804 patients. Br J Gen Pract. 2010;60(576):277-284.

5. National Institute for Health and Care Excellence. Chronic obstructive pulmonary disease: management of chronic obstructive pulmonary disease in adults in primary and secondary care. 2010. Available from: http://www.nice.org.uk/nicemedia/live/13029/49425/49425.pdf. Accessed October 18, 2013.
6. Feldman GJ. Improving the quality of life in patients with chronic obstructive pulmonary disease: focus on indacaterol. Int $J$ Chron Obstruct Pulmon Dis. 2013;8:89-96.

7. Feldman G, Siler T, Prasad N, et al. Efficacy and safety of indacaterol 150 microg once-daily in COPD: a double-blind, randomised, 12-week study. BMC Pulm Med. 2010;10:11.

8. Jones PW, Barnes N, Vogelmeier C, Lawrence D, Kramer B. Efficacy of indacaterol in the treatment of patients with COPD. Prim Care Resp J. 2011;20(4):380-388.

9. Donohue JF, Fogarty C, Lotvall J, et al. Once-daily bronchodilators for chronic obstructive pulmonary disease: indacaterol versus tiotropium. Am J Respir Crit Care Med. 2010;182(2):155-162.

10. Kornmann $\mathrm{O}, \mathrm{Dahl} \mathrm{R}, \mathrm{Centanni} \mathrm{S}$, et al. Once-daily indacaterol versus twice-daily salmeterol for COPD: a placebo-controlled comparison. Eur Respir J. 2011;37(2):273-279.

11. Donohue JF, Singh D, Kornmann O, Lawrence D, Lassen C, Kramer B. Safety of indacaterol in the treatment of patients with COPD. Int $J$ Chron Obstruct Pulmon Dis. 2011;6:477-492.

12. Rodrigo GJ, Neffen H. Comparison of indacaterol with tiotropium or twice-daily long-acting beta-agonists for stable COPD: a systematic review. Chest. 2012;142(5):1104-1110.

13. Burge S, Wedzicha JA. COPD exacerbations: definitions and classifications. Eur Respir J Suppl. 2003;41:46s-53s.

14. Chapman KR, Rennard SI, Dogra A, Owen R, Lassen C, Kramer B. Long-term safety and efficacy of indacaterol, a long-acting $\beta_{2}$-agonist, in subjects with COPD: a randomized, placebo-controlled study. Chest. 2011;140(1):68-75.

15. Dahl R, Chung KF, Buhl R, et al. Efficacy of a new once-daily longacting inhaled beta2-agonist indacaterol versus twice-daily formoterol in COPD. Thorax. 2010;65(6):473-479.

16. Mroz RM, Minarowski L, Chyczewska E. Indacaterol add-on therapy improves lung function, exercise capacity and life quality of COPD patients. Adv Exp Med Biol. 2013;756:23-28.

17. Mahler DA, D’Urzo A, Bateman ED, et al. Concurrent use of indacaterol plus tiotropium in patients with COPD provides superior bronchodilation compared with tiotropium alone: a randomised, double-blind comparison. Thorax. 2012;67(9):781-788.

18. van Noord JA, Buhl R, Laforce C, et al. QVA149 demonstrates superior bronchodilation compared with indacaterol or placebo in patients with chronic obstructive pulmonary disease. Thorax. 2010;65(12): 1086-1091.

19. Bateman ED, Ferguson GT, Barnes N, et al. Dual bronchodilation with QVA149 versus single bronchodilator therapy: the SHINE study. Eur Respir J. Epub May 30, 2013. Available from: doi: 10.1183109031936 .00200212$.

20. Vogelmeier CF, Bateman ED, Pallante J, et al. Efficacy and safety of once-daily QVA149 compared with twice-daily salmeterol-fluticasone in patients with chronic obstructive pulmonary disease (ILLUMINATE): a randomised, double-blind, parallel group study. Lancet Respir Med. 2013;1(1):51-60.

\section{Publish your work in this journal}

The International Journal of COPD is an international, peer-reviewed journal of therapeutics and pharmacology focusing on concise rapid reporting of clinical studies and reviews in COPD. Special focus is given to the pathophysiological processes underlying the disease, intervention programs, patient focused education, and self management protocols.

\section{Dovepress}

This journal is indexed on PubMed Central, MedLine and CAS. The manuscript management system is completely online and includes a very quick and fair peer-review system, which is all easy to use. Visit http://www.dovepress.com/testimonials.php to read real quotes from published authors. 